\title{
Oxidative Depolymerization of Polysaccharides Induced by the Ascorbic Acid-Copper Ion Systems
}

\author{
Koji UCHIDA and Shunro KawaKISHI \\ Department of Food Science and Technology, Nagoya University, \\ Furo-cho, Chikusa-ku, Nagoya 464, Japan
}

Received May 1, 1986

\begin{abstract}
Oxidative depolymerization of several polysaccharides induced by oxygen radical generating systems such as ascorbic acid-copper ion was investigated by the increases in their reducing powers and by gel-filtration. All polysaccharides used in these experiments were greatly depolymerized within $24 \mathrm{hr}$ at room temperature. We thought that the main factors in the oxidation of these polysaccharides were the actions of hydroxyl radical $(\cdot \mathrm{OH})$ generated from the autoxidation of ascorbic acid.

On the other hand, dextrans having molecular weights above $10^{3} \sim 10^{4}$ were more susceptible to the oxidation reaction with $\cdot \mathrm{OH}$ than smaller oligosaccharides $\left(\mathrm{MW}<10^{3}\right)$, and we estimated that the formation of sugars-copper ion complexes was highly important to the oxidative depolymerization of polysaccharides.
\end{abstract}

In the deterioration of biopolymers, aging, and cancer, much attention has been paid to the oxygen radicals and furthermore to the interactions between the oxygen radicals and several tissues and living cell constituents. ${ }^{1)}$ Especially, in the interactions between sugars and ascorbic acid (AsA) in the presence of copper ion, great decreases of viscosity due to the depolymerization of polysaccharides have already been demonstrated by other workers, ${ }^{2 \sim 4)}$ and it was estimated that these phenomena were caused by the action of superoxide anion radical $\left(\mathrm{O}_{2}^{-}\right)$and related radical species generated from the AsA-copper ion systems.

On the other hand, interactions of $\beta$-cyclodextrin as a model compound of polysaccharides with the AsA-copper ion systems has been also reported ${ }^{5)}$ and D-glucose and Darabinose were identified as the reducing terminals of oxidatively cleaved $\beta$-cyclodextrin. From the effects of several scavengers, it was concluded that the main oxidizing factor was the hydroxyl radical $(\cdot \mathrm{OH})$ which $a b-$ stracted a hydrogen atom from the glucose molecule, and this was followed by its oxi- dative degradation.

Though the depolymerizations of biopolymers such as polysaccharides could be attributed to the actions of $\cdot \mathrm{OH}$ generated from the AsA-copper ion systems, the detailed interactions and the differences of reactivity of . $\mathrm{OH}$ with the biopolymers based on their degree of polymerization remains still unknown.

This report is concerned with our investigations of the oxidative depolymerization of several polysaccharides by the actions of oxygen radicals generated from the AsAcopper ion and $\mathrm{H}_{2} \mathrm{O}_{2}$-copper ion systems, and the reactivities of dextrans differing in their molecular weights with oxygen radicals were also investigated.

\section{MATERIALS AND METHODS}

Materials. Pectin and pullulan were purchased from Nakarai Chemicals Ltd. and dextrans, chondroitin sulfate A, and hyaluronate from Sigma Chemical Company. For gel-filtration, Cellulofine GCL-2000 superfine was obtained from Chisso Chemicals. Other reagents were the best grades commercially available. 
Preparation of the interaction systems. The reaction in the AsA-copper ion system was done in $25 \mathrm{ml}$ of $1 / 15 \mathrm{M}$ phosphate buffer ( $\mathrm{pH} 7.2$ ) containing of $0.02 \%$ or $0.04 \%$ polysaccharides, $2 \mathrm{~mm} \mathrm{AsA}$, and $10 \mu \mathrm{M} \mathrm{CuSO}_{4}$, while the reactions in the $\mathrm{H}_{2} \mathrm{O}_{2}$-copper ion system were done in the solutions containing $0.02 \%$ polysaccharides, $1 \mathrm{mM} \mathrm{H}_{2} \mathrm{O}_{2}$, and $10 \mu \mathrm{M} \mathrm{CuSO}$. The reaction mixtures were kept for $24 \mathrm{hr}$ at room temperature and the reactions were ended by the addition of EDTA $(40 \mu \mathrm{M})$.

Gel-filtration. Gel-filtration on Cellulosine GCL-2000 superfine column $(2.8 \times 48 \mathrm{~cm})$ was done as follows. The reaction mixtures were dialysed overnight against 5 liters of distilled water. The non-dialyzable fraction was con- centrated by freeze-drying, put on a gel column, and eluted with $0.1 \% \mathrm{NaCl}$ solution. The eluted sugars were measured colorimetrically by the phenol-sulfate method for neutral polysaccharides and the carbazole-sulfate method for acidic polysaccharides.

Elution volumes of standard dextrans were $120 \mathrm{ml}$ (MW $5 \times 10^{5}$ ), $156 \mathrm{ml} \quad\left(\mathrm{MW} 7 \times 10^{4}\right), 160 \mathrm{ml} \quad(\mathrm{MW}$ $\left.4 \times 10^{4}\right)$, and $197 \mathrm{ml}\left(\mathrm{MW} 10^{4}\right)$ respectively.

Colorimetric measurement for the depolymerization of polysaccharides. The course of depolymerization of polysaccharides induced by the AsA-copper ion and $\mathrm{H}_{2} \mathrm{O}_{2}-$ copper ion systems were measured by the Park-Johnson method as the increase of reducing sugars.

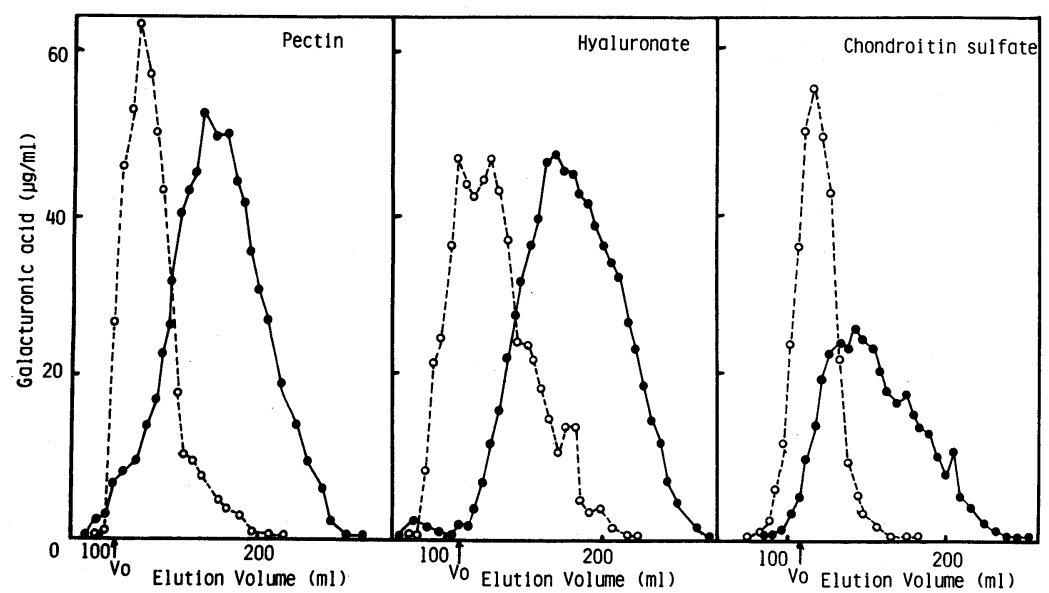

FIG. 1A. Gel-filtration on Cellulofine GCL-2000 Superfine Column of Acidic Polysaccharides before and after Treatment with the $\mathrm{AsA}-\mathrm{Cu}^{2+}$ System.

--- --- , before; - - - after. Experiments were done with $0.04 \%$ polysaccharides, $2 \mathrm{~mm} \mathrm{AsA}$, and $10 \mu \mathrm{M} \mathrm{Cu}{ }^{2+}$ in $1 / 15 \mathrm{M}$ phosphate buffer $(\mathrm{pH} 7.2)$ at room temperature.
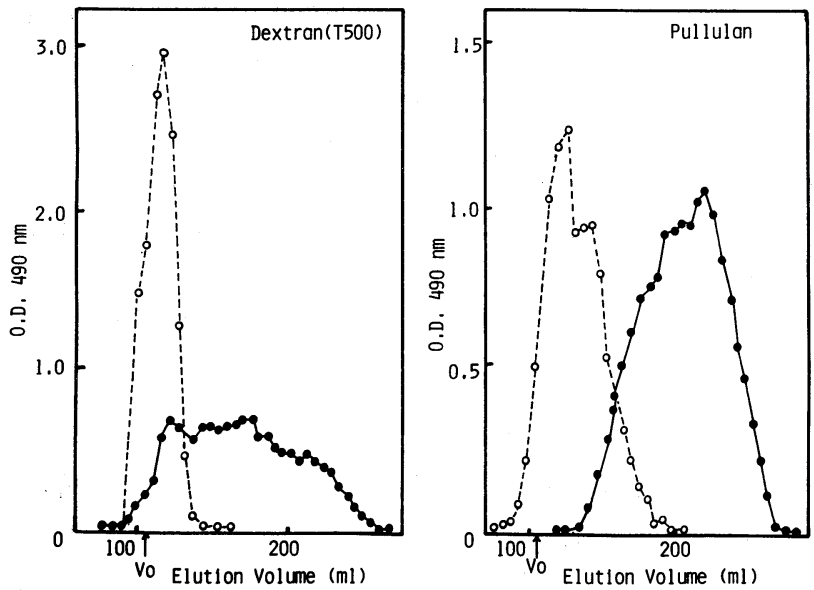

FIG. 1B. Gel-filtration on Cellulofine GCL-2000 Superfine Column of Neutral Polysaccharides before and after Treatment with the $\mathrm{AsA}-\mathrm{Cu}^{2+}$ System.

--- --- , before; - - - after. Experiments were done as described in the legend to Fig. 1A. 
Reducing powers of native polysaccharides $(0.04 \%$, w/v) were O.D. 1.1 (pectin), 0.43 (hyaluronate), 0.60 (pullulan), and 0.38 (dextran T500), and similarly, the same concentrations of standard dextrans were O.D. 80.2 (isomaltose), $47.8\left(\mathrm{MW} \mathrm{10^{3 }}\right), 11.9\left(\mathrm{MW} 5 \times 10^{3}\right), 5.8(\mathrm{MW}$ $\left.10^{4}\right), 1.2\left(\mathrm{MW} 4 \times 10^{4}\right), 0.92\left(\mathrm{MW} 7 \times 10^{4}\right)$, and $0.38(\mathrm{MW}$ $5 \times 10^{5}$ ) respectively. O.D. 0.7 corresponds to $10 \mu \mathrm{g}$ of glucose per milliliter.

\section{RESULTS AND DISCUSSION}

\section{Depolymerization of polysaccharides}

The extent of depolymerization in each polysaccharide was measured by gel-filtration on a Cellulofine GCL-2000 superfine column (Fig. 1A and B). The results showed that both acidic and neutral polysaccharides were greatly depolymerized by the actions of the AsA-copper ion system within $24 \mathrm{hr}$. The degradation of hyaluronic acid and pullulan seemed to be more prominent in this experiment. To find the molecular weights of degradation products, they were compared with those of standard dextrans on a gel chromatogram and their molecular weights were clearly found to be reduced to $5 \times 10^{3}$ $\sim 10^{4}$ from $>10^{5}$ by the actions of oxygen radicals. These depolymerizations of poly-

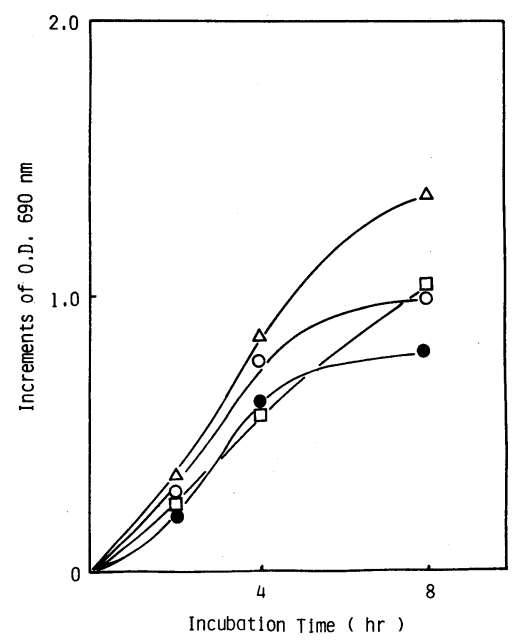

Fig. 2. Depolymerization of Polysaccharides as Measured by the Increase of Reducing Power.

The four symbols refer to pectin $(\bigcirc)$, hyaluronate $(\triangle)$, pullulan $(\square)$, and dextran T500 (O). Experiments were done as described in the legend to Fig. 1A. saccharides were also confirmed by the colorimetric measurement of changes in their reducing power (Fig. 2). The result showed that large increases of reducing power due to the oxidative cleavage of polysaccharides occurred within $8 \mathrm{hr}$.

On the other hand, to identify the radical species related to the degradation of polysaccharides, the effects of chelating agents and radical scavengers on the depolymerization of dextrans were examined. Table I showed that EDTA, as a chelating agent, and catalase completely retarded the depolymerization of dextran and other $\cdot \mathrm{OH}$ scavengers such as potassium thiocyanate, sodium formate, and ethanol were also fairly effective. These results had the same tendency as the scavenger's test for oxidative degradation of $\beta$-cyclodextrin. Consequently, it was ascertained that $\cdot \mathrm{OH}$ would be the main active oxygen radical which was concerned with the depolymerization of polysaccharides in the AsA-copper ion systems. Hydroxyl radical might finally be generated through a Fenton-type reaction in the AsA-copper ion system $(1 \sim 3)$ as follows ${ }^{5,6}$ :

$$
\begin{gathered}
\mathrm{O}_{2} \stackrel{\mathrm{AsA}^{-\mathrm{Cu}^{2+}}}{\longrightarrow} \mathrm{O}_{2}^{-} \stackrel{\mathrm{H}^{+}}{\longrightarrow} \mathrm{H}_{2} \mathrm{O}_{2} \\
\mathrm{Cu}^{2+} \stackrel{\mathrm{O}_{2}^{-}}{\longrightarrow} \mathrm{Cu}^{+} \\
\mathrm{H}_{2} \mathrm{O}_{2}+\mathrm{Cu}^{+} \longrightarrow \cdot \mathrm{OH}+\mathrm{OH}^{-}+\mathrm{Cu}^{2+}
\end{gathered}
$$

Table I. Effects of Chelating Agents AND Radical SCAVENGERS ON OXIDATIVE DEPOLYMERIZATION OF POLYSACCHARIDES ${ }^{a}$

\begin{tabular}{lcc}
\hline Scavengers & Conc. & $\%$ inhibition \\
& \\
\hline None & - & 0 \\
Catalase & $0.75 \mathrm{mg} / 50 \mathrm{ml}$ & 91 \\
SOD & $0.75 \mathrm{mg} / 50 \mathrm{ml}$ & 39 \\
EDTA & $40 \mu \mathrm{M}$ & 89 \\
KSCN & $1 \mathrm{mM}$ & 80 \\
EtOH & $1 \mathrm{mM}$ & 46 \\
Na-formate & $1 \mathrm{~mm}$ & 60 \\
\hline
\end{tabular}

a Experiments were done with polysaccharide (dextran) $0.04 \%$, AsA $2 \mathrm{~mm}$, and $\mathrm{Cu}^{2+} 10 \mu \mathrm{M}$ in $1 / 15 \mathrm{M}$. phosphate buffer ( $\mathrm{pH}$ 7.2) at room temperature.

$b$ The percentage of inhibition was represented by the inhibiting rate of the increase of reducing power at $24 \mathrm{hr}$ after incubation. 
It is well known that $\cdot \mathrm{OH}$ is a powerful oxidant to the constituents of living tissues and, at least in the case of sugars, it has been demonstrated by their $\gamma$-radiolysis in an aqueous system that the chemical action of $\cdot \mathrm{OH}$ is mainly hydrogen abstraction from sugar molecules. ${ }^{7,8)}$

\section{Reactivity of several dextrans with hydroxyl radical}

Getteridge has reported on the formation of complexes between proteins and metal ions, and suggested that the complexes were very important to bring about a site-specific oxidation reaction in the presence of hydrogen peroxide and cause protein damages. ${ }^{9,10}$ ) However, these phenomena may not be limited to proteins but may be applicable to other polymers such as nucleic acids and polysaccharides. To verify this assumption, the relationships between the formation of dextranscopper ion complex and reactivity of dextrans with $\cdot \mathrm{OH}$ were examined in the AsA-copper ion and $\mathrm{H}_{2} \mathrm{O}_{2}$-copper ion systems.

Figure 3 shows the increases in reducing power by the oxidative depolymerization of several dextrans induced by the AsA-copper

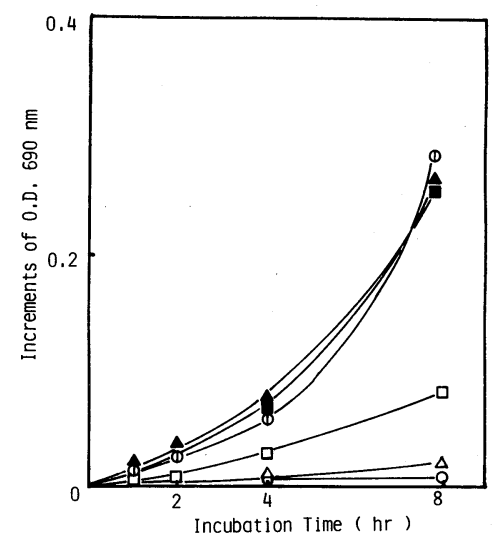

FIG. 3. Depolymerization of Several Dextrans by the $\mathrm{AsA}-\mathrm{Cu}^{2+}$ System as Measured by the Increase of Reducing Power.

The symbols refer to the molecular weight of six dextrans: $(\bigcirc)$, isomaltose; $(\triangle), 10^{3} ;(\square), 5 \times 10^{3}$; (1), $10^{4}$; (A), $7 \times 10^{4} ;(\square), 5 \times 10^{5}$. Experiments were done with $0.02 \%$ polysaccharides, $2 \mathrm{~mm} \mathrm{AsA}$, and $10 \mu \mathrm{M} \mathrm{Cu}{ }^{2+}$ in $1 / 15 \mathrm{M}$ phosphate buffer ( $\mathrm{pH} 7.2)$ at room temperature. ion system. However, oligomers below $10^{3}$ in molecular weight were oxidized to a limited extent in this system, while polymers with $\mathrm{MW}>10^{3}$ were rapidly depolymerized and remained constant beyond $10^{4}$. The same results were also obtained in the $\mathrm{H}_{2} \mathrm{O}_{2}$-copper ion system (Fig. 4). These results suggested that dextrans of high molecular weights $\left(>10^{4}\right)$ formed their copper complexes easily, and oxygen radicals generated near complex sites through the reduction of oxygen would attack the glucose molecules in dextrans. However, dextrans below $10^{3}$ in molecular weight had difficulty in forming complexes with copper ion, and oxygen radicals could not be produced near dextran molecules. Therefore, it seemed that high molecular weight dextrans were more easily attacked by $\cdot \mathrm{OH}$ and depolymerized rapidly than low molecular weight ones. Hydroxyl radical generation in the $\mathrm{H}_{2} \mathrm{O}_{2}$-copper ion systemes was predicted as follows $(4 \sim 7)^{9)}$ :

$$
\begin{aligned}
& \mathrm{Cu}^{2+}+\mathrm{H}_{2} \mathrm{O}_{2} \longrightarrow \mathrm{Cu}^{+}+\mathrm{HO}_{2} \cdot+\mathrm{H}^{+} \\
& \mathrm{HO}_{2} \cdot \longrightarrow \mathrm{H}^{+}+\mathrm{O}_{2}^{-}
\end{aligned}
$$

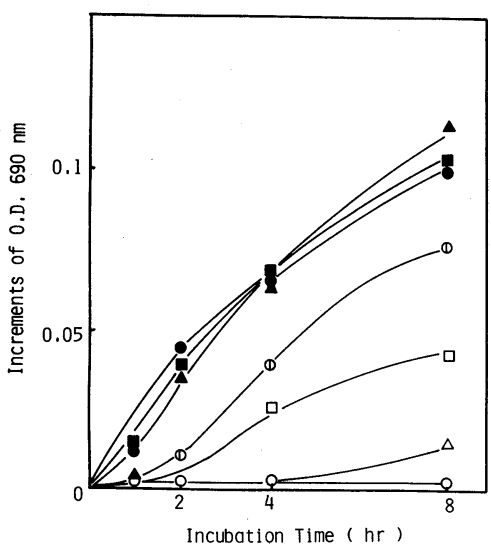

FIG. 4. Depolymerization of Several Dextrans by the $\mathrm{H}_{2} \mathrm{O}_{2}-\mathrm{Cu}^{2+}$ System as Measured by the Increase of Reducing Power.

The symbols refer to the molecular weight of seven dextrans: $(\bigcirc)$, isomaltose; $(\triangle), 10^{3} ;(\square), 5 \times 10^{3}$; (1), $10^{4}$; (○), $4 \times 10^{4} ;(\mathbf{\Delta}), 7 \times 10^{4} ;(\boldsymbol{\square}), 5 \times 10^{5}$. Experiments were done with $0.02 \%$ polysaccharides, $1 \mathrm{mM} \mathrm{H}_{2} \mathrm{O}_{2}$, and $10 \mu \mathrm{M}$ $\mathrm{Cu}^{2+}$ in $1 / 15 \mathrm{M}$ phosphate buffer $(\mathrm{pH} 7.2$ ) at room temperature. 


$$
\begin{aligned}
& \mathrm{Cu}^{2+}+\mathrm{O}_{2}^{-} \longrightarrow \mathrm{Cu}^{+}+\mathrm{O}_{2} \\
& \mathrm{Cu}^{+}+\mathrm{H}_{2} \mathrm{O}_{2} \longrightarrow \mathrm{Cu}^{2+}+\cdot \mathrm{OH}+\mathrm{OH}^{-}
\end{aligned}
$$

Consequently, $\cdot \mathrm{OH}$ might be the main oxidizing agent of dextrans in a similar manner as in the AsA-copper ion systems.

The results obtained from Figs. 3 and 4 suggested that dextrans having molecular weights about $10^{3} \sim 10^{4}$ had the characteristics as polysaccharides corresponding to their molecular weights and the depolymerization rate of dextrans was held constant in a certain molecular weight $\left(>10^{4}\right)$.

It was almost definite that high molecular weight polysaccharides more rapidly formed polymer-metal ion complexes which were susceptible to oxidative reaction by oxygen radicals generated from Fenton-type reactions. Especially, dextran is a well-known polysaccharide easily forming a metal complex. ${ }^{11)}$ Gekko also reported about the molecular weight dependence of dextran-water interactions in the transition region from oligomer to polymer, and discussed the molecular weight dependence of the optical rotation, intrinsic viscosity, and excess thermodynamic functions of dextran in its aqueous solutions. ${ }^{12)}$ It was suggested that several solution properties of dextran changed consistently around $\mathrm{MW}=$ $2 \times 10^{3}$ and conformational or configurational changes of dextran molecules from rodlike (oligomer) to coiled (polymer) form were conducted. The facts obtained from these physiochemical studies seemed to agree fairly well with our results.

As discussed above, the formation of polymer-metal ion complexes were significant for the formation and reaction of oxygen radicals which induced the depolymerization of polysaccharides similarly to the case of proteins $^{9)}$ and, at least for dextrans, their molecular weight was one of the most important factors for complex formation with metal ions.
On the other hand, our results might be closely related to the oxidative depolymerizations of DNA or phage inactivation by oxygen radicals generated from the autoxidation of AsA, ${ }^{13 \sim 16)}$ and it is possible that such high reactivities of DNA with oxygen radicals are due to its complex formation properties with metal ions. Further studies will be needed to clarify such a prediction.

Acknowledgment. The authors thank Professor M. Namiki and Dr. K. Gekko for their helpful advices and discussions.

\section{REFERENCES}

1) R. S. Sohal (ed.), “Age Pigments," Elsevier/NorthHolland, Amsterdam, 1981.

2) A. Herp, T. Rickards, G. Matsumura, L. B. Jakosalem and W. Pigman Carbohydr. Res., 4, 63 (1967).

3) G. Matsumura and W. Pigman, Arch. Biochem. Biophys., 110, 526 (1965).

4) S. F. Wong, B. Halliwell, R. Richmond and W. R. Skowroneck J. Inorg. Biochem., 14, 127 (1981).

5) K. Uchida and S. Kawakishi Agric. Biol. Chem., 50, 367 (1986).

6) E. Shinar, T. Navok and M. Chevion J. Biol. Chem., 258, 14778 (1983).

7) S. Kawakishi, Y. Kito and M. Namiki Carbohydr. Res., 39, 263 (1975).

8) S. Kawakishi, Y. Kito and M. Namiki Agric. Biol. Chem., 41, 951 (1977).

9) J. M. C. Gutteridge and S. Wilkins, Biochim. Biophys. Acta, 759, 38 (1983).

10) B. Cooper, J. M. Creeth and A. S. R. Donald Biochem. J., 228, 615 (1985).

11) C. R. Ricketts Progr. Org. Chem., 5, 73 (1961).

12) K. Gekko, "Solution Properties of Polysaccharides," ed. by D. A. Brant, ACS Symposium Series, American Chemical Society; Washington D. C., 1981, p. $415 \sim 438$.

13) K. Shinohara, M. So, M. Nonaka, K. Nishiyama, H. Murakami and H. Omura, J. Nutr. Sci. Vitaminol., 29, 671 (1983).

14) S. H. Chiou J. Biochem., 94, 1259 (1983).

15) S. H. Chiou J. Biochem., 96, 1307 (1984).

16) A. Murata and K. Kitagawa Agric. Biol. Chem., 37, 1145 (1973). 